\title{
Particularities of Sleep Habits in School Children from Tîrgu Mureș
}

\author{
Sólyom Réka¹, Baghiu Maria Despina², Neagoș Adriana³ \\ 1 University of Medicine and Pharmacy, Tîrgu Mures, Romania \\ 2 Department of Pediatrics 1, County Emergency Clinical Hospital, Tîrgu Mureș, Romania \\ 3 Oto-rhino-laryngology Clinic, Tîrgu Mureș, Romania
}

\begin{abstract}
Introduction: The international literature gives us very variable data regarding sleep disorders and the complaints related to this pathology. However, interpreting these data is difficult because of the ethnical and cultural differences and the numerous possibilities of the assessments. In this paper the authors examined and evaluated the main parameters which characterize the sleep habits of a group of children in Romania, as well as the complaints related to it, which could influence the quality of sleeping.

Material and method: Distributing questionnaires amongst children in Tîrgu Mureș. We used different questionnaires, based on the Epworth and Conner's scores, for children between 11-14 and 15-18 years and for their parents.

Results: The gender ratio was approximately equal, the height and weight of the children was within the framework of Romanian standards. The most frequent nocturnal complaints were: problems with falling asleep, agitation, awakenings during the night. The most frequent daytime complaints: fatigue when in school, difficulty waking up in the morning and mood swings. The results showed significant differences between weekday sleeping hours and weekend sleep time $(p=0.0022)$.

Conclusion: Sleep habits change with age, which is a physiological effect. Other factors that modify sleeping habits in a negative way and reduce the time spent sleeping, play a crucial role in the occurrence of persistent fatigue, reduced quality school performance and even of a depraved life quality.
\end{abstract}

Keywords: sleep habits, children, weekdays, life quality

Received: 30 April 2013

\section{Introduction}

The international literature provides us various data regarding sleep disorders and complaints related to this pathology, especially the sleep patterns of school-aged children $[1,2,3,4]$. The interpretation of these data is complicated by the present ethnic and cultural differences and the variety of possibilities for the assessment. Therefore, we decided to examine and evaluate the main parameters that characterize sleeping habits and sleep-related complaints that may affect its quality, in a group of children from Romania.

To the best of our knowledge, there has not been conducted any study in Romania to examine this issue. This paper presents data on sleeping habits in schoolchildren: time spent with sleeping, quality of sleep, frequency of sleep-related complaints.

The main inquiries, we were seeking answers to were:

- the frequency of sleep-related disorders which appear in childhood;

- the most frequently met complaints related to this issue, and whether these complaints can be an early sign of obstructive sleep apnea (OSA).

\section{Material and method}

In this study we surveyed schoolchildren from Tîrgu Mureș. We used different questionnaires for young school children

Correspondence to: Réka Sólyom

E-mail: solyom.reka@umftgm.ro
(11-14 years old) and secondary school adolescents (15-18 years old). The total number of distributed questionnaires was 552, out of which 94 to young school children, 339 to secondary school adolescents and 89 to parents. The questionnaires were developed by the authors of this study to identify and evaluate sleep hygiene and sleep-related complaints in young school aged children and adolescents. The questionnaires were based on data published in the international literature and on other standard questionnaires used to assess sleep quality $[5,6]$. The reason for developing our own questionnaires was that presently we could not find any complex questionnaire to assess both sleep-related complaints and factors that influence them, thus we could achieve a more extensive interpretation of the complaints.

The set of questions for both age groups inquired the followings:

- Age, gender and year of study;

- Anthropomorphic data: weight, height, BMI, weight and height percentiles;

- Sleep hygiene:

- bedtime and wake-up time during weekdays and weekends;

- sleeping conditions: own room, own bed, bedtime routine, presence of parents when falling asleep;

- activities before bedtime: TV, internet, music, books;

- consumption of beverages, energy substances during the day or before going to bed. 
Table I. Time spent sleeping

\begin{tabular}{lcc}
\hline & $\begin{array}{c}\text { Young school } \\
\text { children }\end{array}$ & Adolescents \\
\hline $\begin{array}{l}\text { Time spent sleeping on weekdays } \\
\text { (hours } \pm \text { SD) }\end{array}$ & $8.5 \pm 0.8$ & $7.6 \pm 0.8$ \\
$\begin{array}{l}\text { Time spent sleeping on weekends } \\
\text { (hours } \pm \text { SD) }\end{array}$ & $10.3 \pm 1.3$ & $9.9 \pm 1.3$ \\
Optimal values (hours) & $10-11$ & $8-9$ \\
\hline
\end{tabular}

- Anamnesis: tonsillectomy, adenoidectomy, chronic illness, chronic medication;

- Frequency of sleep-related complaints.

We performed the evaluation of sleep cycle in children based on their answers to our inquiries: "What time do you go to sleep on weekdays?", "What time do you wake up?", "What time do you go to sleep on weekends?", "What time do you wake up?". Considering the range of morning and evening hours mentioned by children, we calculated the time spent sleeping.

Sleep-related complaints were assessed as daytime and nighttime symptoms. Children also provided data about the frequency of their complaints.

Data were pooled in Microsoft Office Excel files and then processed with the Mann-Whitney, Kruskal-Wallis and Fischer tests.

\section{Results}

The average age of young school children was $12.58 \pm 1.2$ years, the gender ratio was slightly higher for girls, $51.1 \%$, and the average age for adolescents was $15.80 \pm 0.9$ years and the gender ratio was $51.3 \%$ boys and $48.7 \%$ girls. The average height and weight percentile was between 50-75 in both groups.

Time spent sleeping in both groups and optimal values are shown in Table I.

After analyzing periods of sleep, the Kruskal-Wallis test showed a statistically significant difference $(p=0.0022)$ regarding the modification of sleep duration with increasing age. When comparing the two age groups we found that time spent sleeping during the week is significantly shorter

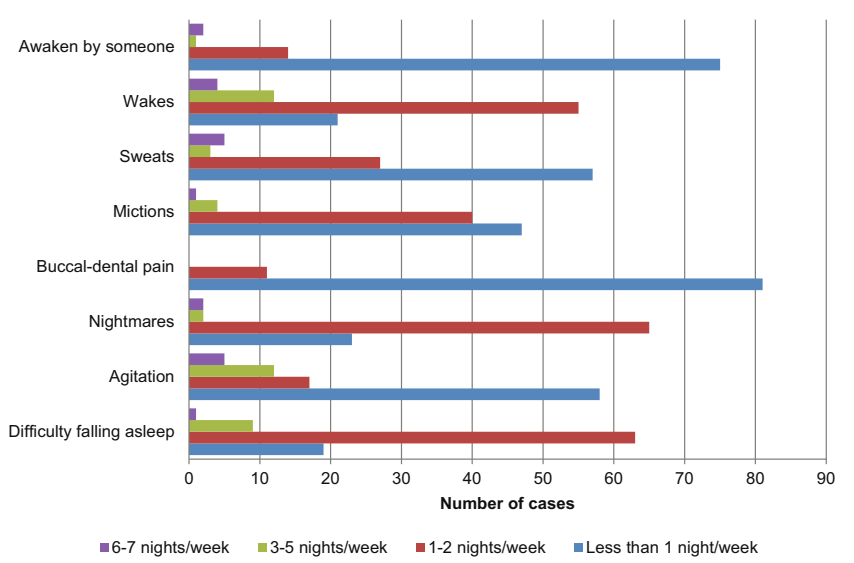

Fig. 1. Frequency of sleep related complaints in young school children in adolescents $(\mathrm{p}<0.05)$. But on weekends there were no obvious differences.

The most common complaints occurring during sleep were: difficulty falling asleep, agitation during sleep and waking up during the night, complaints that were present in both groups at a rate of 10-15\% (Figures 1 and 2).

Difficulty falling asleep occurred in $68.5 \%$ of the children with a frequency of 1-2 nights per week and in 9.8\% with a frequency of 3-5 times per week. Agitation during the night was present in a proportion of $13-18.5 \%$ and $70.7 \%$ of the children were affected by nightmares with moderate frequency (1-2 nights per week). Sudden awakenings during the night were characteristic in $13-59.8 \%$ of the cases (frequency: 3-5 times/week - 1-2 times/week).

In adolescents these nocturnal complaints were present in a smaller percentage: difficulty falling sleep $10.4-18.1 \%$, agitation during sleep $6.5-8.7 \%$, nightmares occurred in $1.5-13.6 \%$ of the cases (frequency: $3-5$ times/week and 1-2 times/week).

In our survey we observed that buccal-dental pain in the morning, which could be an indirect sign of bruxism, was present in $16.8 \%$ of adolescents and in $9.5 \%$ of young children. Restless leg syndrome was present in $6 \%$ of adolescents (we considered only those cases that were reported with a higher frequency).

The most common daytime complaints were morning fatigue, feeling tired at school, waking up with difficulty. These complaints were present in both groups with a higher frequency, at a rate of $20-35 \%$.

Emphasized drowsiness during the day was characterized by daytime complaints such as falling asleep at school or afternoon naps. Drowsiness at school was present in about $30 \%$ of adolescents with different frequency and in only $3 \%$ of young children (Figures 3 and 4 ).

Afternoon nap during the week was regularly present in $44.6 \%$ of young children and in $17 \%$ of adolescents. According to data obtained after the survey we could observe a statistically significant association $(\mathrm{p}<0.0214)$ between the presence and absence of afternoon nap and grading at school in young children. Thus, children who took a nap in the afternoon had lower grades. We found that in $24 \%$ of

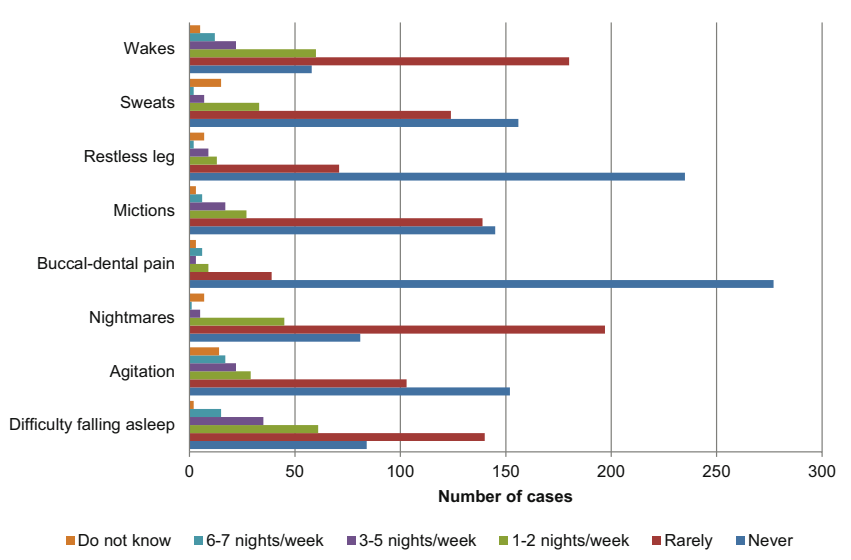

Fig. 2. Frequency of sleep related complaints in adolescents 


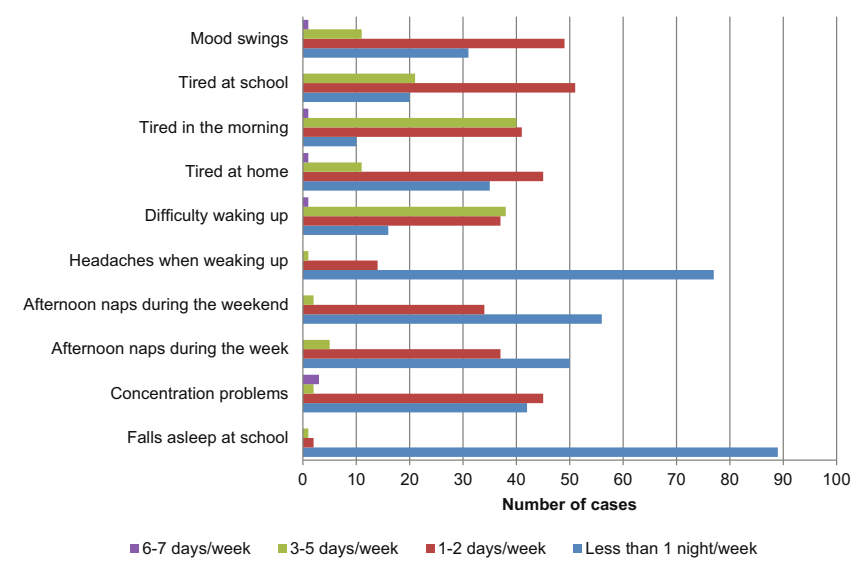

Fig. 3. Frequency of daytime complaints in young school children

the children there was an association between the presence/ absence of afternoon naps and difficulty concentrating.

In case of adolescents this association was not significant, but there was a difference between the two groups (those who usually take an afternoon nap and those who do not), those who took an afternoon nap had higher grades than the others.

We found that there was a statistically significant difference ( $\mathrm{p}<0.0193)$ regarding time spent sleeping and time spent watching TV on weekdays. Thus, in case of adolescents who spend $\geq 5$ hours per day watching TV we noticed a shortened sleeping time (7.5 hours \pm 0.9$)$ in comparison with those who do not watch TV at all or less than 1 hour per day (7.8 hours \pm 0.9$)$.

We also found a statistically significant difference ( $\mathrm{p}$ $<0.0289$ ) among adolescents who used the internet frequently ( $\geq 5$ hours/day) and their sleeping time $(7.4 \pm 0.9$ hours) and those who used it less time (none or 1 hour/ day) and their sleeping time (7.6 \pm 0.9 hours).

Daytime and sleep related complaints also occur more frequently in those who watch TV and use the Internet on a regular basis.

The consumption of food and energy drinks was observed in $95 \%$ of adolescents, 35\% consumed them just before bedtime.

\section{Discussions}

Our survey shows decreased sleep time in both children and adolescents (1-2 hours) in comparison to the recommended values $[7,8,9]$, which can be considered a significant decrease, because during this period the body passes through almost one sleep cycle, thus skipping a Delta and a REM phase [10]. This shortening has been described by other authors too in the international literature $[11,12,13,14]$. Time spent sleeping calculated for weekdays showed a decreased duration with increasing age, which may also be physiological $[15,16,17]$. Besides this physiological shortening we can also observe the presence of other factors that can contribute to the shortening of sleep time $[18,19,20]$. This can be supported by the fact that the duration of sleep time calcu-

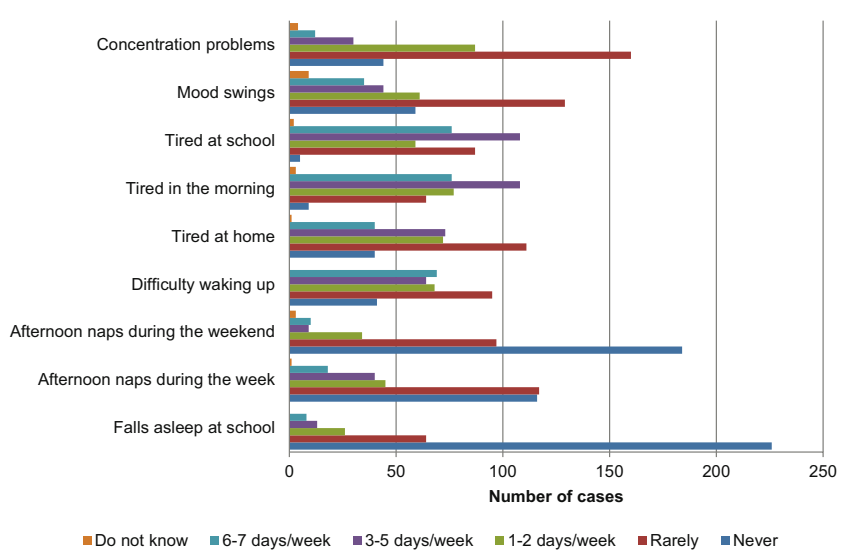

Fig. 4. Frequency of daytime complaints in adolescents

lated by us is shorter compared to the recommended values in both age groups and compared to this significant shortening, sleep time on weekends remains unchanged. Shortening of sleep time in adolescents and also an increased need for sleep has been demonstrated by several studies $[21,22,23,24]$. Prolonged sleep time during weekends and holidays may be explained by the fact that sleep deficit occurring during the week is recovered under this form [25]. Studies referring to overall sleep complaints show similar results to those obtained in our study $[26,27,28]$.

A study performed in India on children aged 14 to 18 years showed the presence of awakenings during the night in $37 \%$ of the children with an average frequency of 3 times per week. The duration of sleep time showed a tendency of decrease with increasing age and daytime drowsiness [29,30]. Another study conducted in China and Germany among school children showed the prevalence of sleep complaints as: difficulty falling asleep, awakenings during the night, agitation during sleep in $20-30 \%$ of children with a frequency of $2-4$ times per week. The following were also described: the presence of sleep talking (15-22\%) and fatigue during the day (1624\%) [31,32].

The rate of daytime and nighttime complaints shows a different situation that depends on age [33]. Besides the relatively constant frequency of daytime complaints the presence of nighttime complaints shows a decrease with increasing age. This can be explained based on data published in the international literature. Thus, daytime drowsiness is more common in older children compared to younger ones, who are characterized by hyperactivity.

\section{Conclusions}

Our results have shown that the duration of sleep time in school age children from Tîrgu Mureș is below the recommended values.

Sleep related complaints are common in both children and adolescents. Nighttime complaints are more frequent in young school children and daytime complaints in adolescents. 
Most adolescents consume energy drinks and food, some of them just before bedtime, which may adversely affect the quality and quantity of sleep.

Watching television or surfing the internet may have negative consequences regarding sleep time, quality of sleep and sleep-related complaints.

However, sleep disorder in childhood represents a rather common pathology, and based on both data published in the international literature and our results, we can state that currently it is underdiagnosed. The presence of longterm adverse reactions, increased frequency of sleep-related complaints and the possibility to prevent or treat these disorders suggests the importance of further developing investigation, diagnosis and therapeutic methods.

\section{Acknowledgement}

This paper is partially supported by the Sectoral Operational Programme Human Resources Development, financed from the European Social Fund and by the Romanian Government under the contract number POSDRU/ 80641.

\section{References}

1. Acebo C, Sadeh A, Seifer R, et al. Estimating sleep patterns with activity monitoring in children and adolescents: how many nights are necessary for reliable measures? Sleep. 1999;22(1):95-103.

2. Anderson J, Foster J, Goodenough F. The sleep of young children. Pedagog Semin J Genet Psychol. 1928;35(2):201-217.

3. Bauer K, Blunden SL. How accurate is subjective reporting of childhood sleep patterns: a review of the literature and implications for practice. Current Pediatric Reviews. 2008;4(2):132-142.

4. Chant N, Blatz W. A study of sleeping habits of children. In: Bott E, Blatz W, Chant N, Bott H, eds. Genetic Psychology Monographs: Child Behaviour, Differential and Genetic Psychology. Clark University (Worcester, MA), Toronto, Canada: 1928:13-43.

5. Gaina A, Sekine M, Chen X, Hamanishi S, Kagamimori S. Validity of child sleep diary questionnaire among junior high school children. J Epidemiol. 2004;14(1):1-4.

6. Strauch I, Meier B. Sleep need in adolescents: a longitudinal approach. Sleep 1988;11:378-386.

7. Read M. The physical care of young children. In: The Mothercraft Manual. New York, NY: Little, Brown, and Company; 1916.

8. Terman L, Hocking A. The sleep of school children: Its distribution according to age, and its relation to physical and mental efficiency. J Educ Psychol. 1913;4(3):138-147.

9. Teufel J, Brown S, Birch D. Sleep among early adolescent students. Am J Health Studies. 2007;22(1):10-17.

10. Harrison Y, Horne JA. Should we be taking more sleep? Sleep. 1995;18(10):901-907.
11. Dorofaeff TF, Denny S. Sleep and adolescence. Do New Zealand teenagers get enough? J Paediatr Child Health. 2006;42(9):515-520.

12. Matricciani LA, Olds TS, Blunden S, Rigney G, Marie T. Never Enough Sleep: A Brief History of Sleep Recommendations for Children. Pediatrics 2012;129:548.

13. Oka Y, Suzuki S, Inoue Y. Bedtime activities, sleep environment, and sleep/ wake patterns of Japanese elementary school children. Behav Sleep Med. 2008;6(4):220-233.

14. Olds T, Blunden S, Petkov J, Forchino F. The relationships between sex, age, geography and time in bed in adolescents: a metaanalysis of data from 23 countries. Sleep Med Rev. 2010;14(6):371-378.

15. Lumeng J. Future directions for research on sleep durations in pediatric populations. Sleep. 2010;33(10):1281-1282.

16. NOVÁK, M. Alvás-és ébrenléti zavarok diagnosztikája és terápiája. Budapest, OKKER, 2000. pp. 42-43.

17. Sekine M, Chandola T, Martikainen P, Marmot M, Kagamimori S. Work and family characteristics as determinants of socioeconomic and sex inequalities in sleep: the Japanese Civil Servants Study. Sleep. 2006; 29(2):206-216.

18. Kuriyama K, Stickgold R, Walker MP. Sleep-dependent learning and motor-skill complexity. Learn Mem. 2004;11(6):705-713.

19. Reynolds M, Mallay H. The sleep of young children. J Genet Psychol. 1933;43:322-351.

20. Sadeh A, Gruber R, Raviv A. The effects of sleep restriction and extension on schoolage children: what a difference an hour makes. Child Dev. 2003;74(2):444-455.

21. Carskadon MA. Patterns of sleep and sleepiness in adolescents. Paediatrician. 1990;17(1):5-12.

22. Mindell JA, Owens J, Alves R, et al. Give children and adolescents the gift of a good night's sleep: a call to action. Sleep Med. 2011;12(3):203-204.

23. Warner S, Murray G, Meyer D. Holiday and school-term sleep patterns of Australian adolescents. J Adolesc. 2008;31:595-608.

24. Wing YK, Li SX, Li AM, Zhang J, Kong AP. The effect of weekend and holiday sleep compensation on childhood overweight and obesity. Pediatrics. 2009;124:994-1000.

25. Walsh J, Dement W, Dinge D. Sleep medicine, public policy, and public health. In: Kryger M, Roth T, Dement W, eds. Principles and Practice of Sleep Medicine. Philadelphia, PA: Elsevier/Saunders; 2005:648-656.

26. Blunden S, Hoban TF, Chervin RD. Sleepiness in children. Sleep Med Clin. 2006;1(1):105-118.

27. Heussler HS. Common causes of sleep disruption and daytime sleepiness: childhood sleep disorders II. Med J Aust. 2005;182(9):484-489.

28. Howard BJ, Wong J. Sleep disorders. Pediatr Rev. 2001;22(10):327-342.

29. Baumecker W. Die Schlafzeit des Kleinkindes. Deutsche Gesundh Wes. 1958;13(16):496-499.

30. Gupta R et al. Sleep patterns of urban school-going adolescents. Indian Pediatr. 2008;45:183-189.

31. Bernhard L. Beitrag zur Kenntnis der Schlafverhältnisse Betliner Gemeindeschüler. Beitr Kin-derf Heilerziehung. 1907;39(5):5-13.

32. Loessl B, Valerius G, Kopasz M, Hornyak M, Riemann D, Voderholzer $U$. Are adolescents chronically sleep-deprived? An investigation of sleep habits of adolescents in the Southwest of Germany. Child Care Health Dev. 2008;34(5):549-556.

33. Wolfson AR, Carskadon MA, Acebo C, et al. Evidence for the validity of a sleep habits survey for adolescents. Sleep. 2003;26(2):213-216. 